\title{
Jugular Bulb Oximetry for Prediction of Vasospasm Following Subarachnoid Hemorrhage
}

\author{
Navraj S. Heran, Stephen J. Hentschel, Brian D. Toyota
}

\begin{abstract}
Background: Cerebral vasospasm adversely impacts the outcome of those suffering aneurysmal subarachnoid hemorrhage (SAH). Prediction of vasospasm could improve outcomes. We hypothesized that preclinical vasospasm would be heralded by an increase in cerebral oxygen extractions $\left(\mathrm{AVDO}_{2}\right)$ which could be detected by jugular bulb oximetry. A pilot study was conducted to address this hypothesis. Methods: Fourteen consenting patients with aneurysmal SAH, undergoing early surgery, were entered into the study. Four patients were withdrawn from the study secondary to failure of catheters or religious belief. At the time of craniotomy, a jugular bulb catheter was placed. Post-operatively, arterial and jugular bulb blood samples were taken every 12 hours to calculate $\mathrm{AVDO}_{2}$. As this was an observational study, no change in management occurred based on measurements. Results: Four of 10 patients had clinical vasospasm. These patients had a significant rise in $\mathrm{AVDO}_{2}$ approximately one day prior to the onset of neurologic deficits $(\mathrm{P}<0.001)$. Symptoms resolved along with a significant improvement in $\mathrm{AVDO}_{2}$ on instituting hypertensive, hemo-dilutional, and hypervolemic therapy in these patients. The six patients who did not exhibit clinical vasospasm did not demonstrate significant rise in $\mathrm{AVDO}_{2}$. Conclusions: Jugular bulb oximetry is simple and cost effective. Increases in $\mathrm{AVDO}_{2}$ using this technique were predictive of clinically evident vasospasm in the subsequent hours to days. This investigation supports a larger study to assess the utility of jugular bulb oximetry in predicting vasospasm in aneurysmal SAH.
\end{abstract}

RÉSUMÉ: Oxymétrie du bulbe jugulaire pour prédire le vasospasme suite à une hémorragie sous-arachnö̈dienne. Introduction: Le vasospasme cérébral a un impact négatif sur l'évolution des patients qui présentent une hémorragie sous-arachnoïdienne (HSA) d'origine anévrismale. La possibilité de prédire le vasospasme pourrait améliorer le pronostic chez ces patients. Selon notre hypothèse, le vasospasme préclinique serait précédé d'une augmentation de l'extraction d'oxygène au niveau cérébral $\left(\mathrm{DAVO}_{2}\right)$ qui pourrait être détectée par oxymétrie du bulbe jugulaire. Une étude pilote a été réalisée pour vérifier cette hypothèse. Méthodes: Quatorze patients présentant une HSA anévrismale, ayant consenti à participer à l'étude et devant subir une chirurgie tôt après l'événement, ont été recrutés. Quatre patients ont été retirés de l'étude pour des raisons techniques ou des motifs religieux. Au moment de la craniotomie, un cathéter a été introduit dans le bulbe jugulaire. Après l'intervention, des échantillons de sang artériel et de sang du bulbe jugulaire ont été prélevés aux 12 heures pour calculer la $\mathrm{DAVO}_{2}$. Comme il s'agissait d'une étude d'observation, les mesures effectuées n'ont pas modifié la conduite thérapeutique. Résultats: Quatre des 10 patients ont eu un vasospasme clinique. Ces patients avaient une augmentation significative de la $\mathrm{DAVO}_{2}$ environ une journée avant le début des déficits neurologiques ( $\left.\mathrm{p}<0,001\right)$. Les symptômes ont régressé et on a noté une amélioration significative de la $\mathrm{DAVO}_{2}$ avec le traitement $\mathrm{HHH}$ (hypovolémie, hémodilution et hypertension) chez ces patients. Les six patients qui n'ont pas présenté de vasospasme clinique n'ont pas eu d'augmentation significative de la $\mathrm{DAVO}_{2}$. Conclusions: L'oxymétrie du bulbe jugulaire est une méthode simple et rentable. L'augmentation de la $\mathrm{DAVO}_{2}$ mesurée par cette technique prédisait la manifestation clinique du vasospasme dans les heures sinon dans les jours suivants. Cette étude justifie d'effectuer une étude de plus grande envergure pour évaluer l'utilité de l'oxymétrie du bulbe jugulaire pour prédire le vasospasme chez les patients atteints de HSA anévrismale.

Can. J. Neurol. Sci. 2004; 31: 80-86

Cerebral vasospasm is a potentially catastrophic, delayed complication of aneurysmal subarachnoid hemorrhage (SAH). Vasospasm is a morphologic narrowing of the cerebral vasculature in response to blood or blood products such as oxyhemoglobin in the extra-vascular space. ${ }^{1}$ After aneurysmal SAH, angiographic vasospasm can be demonstrated in up to $70 \%$ of cases $^{2}$ and clinical vasospasm in $17 \%$ to $40 \%$ of patients. ${ }^{3}$ Vasospasm may occur anywhere from three days to two weeks following the hemorrhage with the potential for devastating delayed ischemic neurological deficits (DINDs). ${ }^{4}$ These DINDs have been demonstrated to occur in approximately $20 \%$ of patients and have significant implications in the management and outcome of patients suffering $\mathrm{SAH} ;{ }^{4}$ about one third of patients suffering DINDs die or have a poor functional outcome. . $^{4,5}$

From the Division of Neurosurgery, Department of Surgery, University of British Columbia, Vancouver, British Columbia, Canada.

ReCEIVEd February 7, 2003. ACCEPTED In FINAL FORM June 25, 2003. Reprint requests to: Brian D. Toyota, 310A - 700 West 10th Avenue, Vancouver, BC Canada V57 4E5 
Vasospasm is often difficult to diagnose, especially in patients with an altered level of consciousness. The time honored Fisher grading scale, correlating the greater amount of subarachnoid blood on initial cranial computed tomography (CT) to the increased likelihood of vasospasm, remains a valuable but very limited and nonspecific method of vasospasm prediction. ${ }^{6}$ Prediction of the onset of vasospasm has been attempted with transcranial doppler (TCD), xenon CT, single-photon emission $\mathrm{CT}$, perfusion-weighted magnetic resonance imaging, positron emission tomography, and conventional catheter angiography. ${ }^{7-10}$ All of these modalities are either expensive, require highly trained support staff, or have a significant risk of major morbidity associated with them. The implementation of prophylactic therapies in all patients has been suggested but has not proven to be beneficial ${ }^{11}$ and is complicated by imposing treatment related risks upon individuals who may never develop symptomatic vasospasm.

We hypothesized that there is a preclinical vasospasm state of ischemia in $\mathrm{SAH}$ that is heralded by changes in cerebral metabolism of oxygen and is detectable by jugular bulb oximetry. The objectives of this study were to:

1) Assess the feasibility and safety of jugular bulb oximetry in the setting of SAH,

2) Determine cerebral oxygen extraction values in this patient population,

3) Assess the change in cerebral oxygen extractions prior to, during, and after treatment of vasospasm,

4) Determine whether clinical vasospasm can be predicted based on the above.

\section{SUBJECTS AND METHODS}

\section{Study protocol}

This was a prospective pilot study designed to assess the feasibility of measurements and the ability of jugular bulb oximetry to detect changes in cerebral metabolism relative to the onset of angiographically confirmed clinical vasospasm in aneurysmal SAH. This was a purely observational study and would not evaluate the effect of this early recognition upon treatment and outcome in patients with aneurysmal SAH at this time.

The Ethics Approval Committee at our institution approved this study. All patients with aneurysmal SAH who were referred to our hospital were potential candidates. Inclusion criteria were as follows: (1) SAH of less than five days; (2) craniotomy for aneurysm management (3) informed and signed consent. A jugular bulb catheter, a single lumen central line with the tip at the origin of the jugular vein in the base of the skull, was placed, by a physician experienced in the technique, on the side with the most blood on the CT scan, or on the right side if the amount of blood was equal between sides as the right internal jugular vein has been shown to drain the majority of the supratentorial compartment. ${ }^{12}$ Catheter position was confirmed with lateral skull radiographs. Routine determination of cerebral oxygen extraction $\left(\mathrm{CEO}_{2}\right)$, also known as the arterio-jugular venous difference of oxygen saturation $\left(\mathrm{AVDO}_{2}\right)$ (Figure 1$)$, was to be performed every 12 hours and with the onset of new neurologic deficits. The catheters were withdrawn at the time when the

\section{$\mathrm{CEO}_{2}=\mathrm{AVDO}_{2}=\mathrm{SaO}_{2}-\mathrm{SjvO}_{2}$}

$\mathrm{CEO}_{2}-$ Cerebral oxygen extraction

$\mathrm{AVDO}_{2}-$ Arterio-jugular venous difference of oxygen saturation

$\mathrm{SaO}_{2}$-Oxygen saturation of arterial blood

$\mathrm{SjvO}_{2}-$ Oxygen saturation of jugular bulb venous blood

Figure 1: Formula to calculate cerebral oxygen extraction

vasospasm window was determined to be over, usually between days 10 to 14 post-SAH.

The measurements alone prompted no changes in management during the study, making this part purely observational. Conversely, no therapy was withheld that would have been given in the normal clinical situation.

\section{Patients}

All patients with aneurysmal SAH who were referred to our hospital were potential candidates for the study. Fourteen consenting patients who met the inclusion criteria were entered into the study.

\section{Patient management}

Patients were treated in standard fashion with blood pressure management to ensure normotension prior to surgery, bed rest, head of bed elevation to 20-30 degrees, oral nimodipine $60 \mathrm{mg}$ every four hours for 21 days, and early implementation of feeding. All patients were monitored in the same intensive care setting with a homogeneous group of nurses. Standard monitoring included continuous hemodynamic via central and arterial lines and pulse oximetry. Clinical vasospasm was said to occur if there was a new onset of a focal neurologic deficit or a change in the neurologic condition without evidence of electrolyte imbalance, seizure activity, medication effect, raised intracranial pressure (ICP), or hematoma as demonstrated on cranial CT. Once clinical vasospasm was noted, hypertensive, hemo-dilutional, and hypervolemic (HHH) therapy was instituted to the endpoints of improvement or resolution of the neurologic deficit, or maximum recommended doses of vasopressor medications or maximum systolic blood pressures of no more than $220 \mathrm{mmHg}$ or complications from the therapy.

\section{Data analysis}

Data was collected prospectively and managed in a spreadsheet file. Paired t-tests were used to compare $\mathrm{AVDO}_{2}$ within groups and unpaired t-tests for between groups using SPSS 7.5 (Statistical Package for the Social Services version 7.5). Significance was established at $\mathrm{p}<0.05$. All results are represented as means with standard deviations and ranges where appropriate.

\section{ReSUlts}

\section{Patient details}

Of 14 study patients, four did not complete the study (29\%). Three were withdrawn secondary to the inability to maintain vascular access and one patient, who was a Jehovah's Witness 


\section{Table 1: Patient characteristics}

\begin{tabular}{|c|c|c|c|c|c|c|c|c|}
\hline Patient & $\begin{array}{l}\text { Age } \\
\text { (Years) }\end{array}$ & Sex & $\begin{array}{l}\text { Hunt and } \\
\text { Hess Grade }\end{array}$ & $\begin{array}{l}\text { Fisher } \\
\text { Grade }\end{array}$ & $\begin{array}{l}\text { Jugular Bulb } \\
\text { Position }\end{array}$ & $\begin{array}{l}\text { Aneurysm } \\
\text { Location }\end{array}$ & $\begin{array}{l}\text { Clinical } \\
\text { Vasospasm }\end{array}$ & $\begin{array}{l}\text { Glasgow } \\
\text { Outcome Score }\end{array}$ \\
\hline 1 & 53 & $\mathrm{~F}$ & 2 & 3 & $\mathrm{R}$ & R MCA & $\mathrm{Y}$ & 4 \\
\hline 2 & 35 & $\mathrm{~F}$ & 3 & 3 & $\mathrm{R}$ & R MCA & $\mathrm{Y}$ & 5 \\
\hline 4 & 44 & $\mathrm{~F}$ & 5 & 3 & $\mathrm{~L}$ & L ICA bifurcation & $\mathrm{Y}$ & 1 \\
\hline 5 & 61 & M & 3 & 3 & $\mathrm{~L}$ & L MCA & $\mathrm{N}$ & 5 \\
\hline 6 & 54 & $\mathrm{~F}$ & 3 & 3 & $\mathrm{R}$ & Acomm & $\mathrm{N}$ & 4 \\
\hline 9 & 72 & $\mathrm{~F}$ & 3 & 3 & $\mathrm{R}$ & R Pcomm & $\mathrm{N}$ & 4 \\
\hline 10 & 49 & M & 2 & 3 & $\mathrm{R}$ & Acomm & $\mathrm{N}$ & 5 \\
\hline
\end{tabular}

$\mathrm{F}=$ female, $\mathrm{M}=$ male, $\mathrm{Y}=\mathrm{yes}, \mathrm{N}=$ no, $\mathrm{R}=$ right, $\mathrm{L}=$ left, $\mathrm{MCA}=$ middle cerebral artery, Pcomm=posterior communicating artery, ICA=internal carotid artery, Acomm=anterior communicating artery aneurysm.

with concerns about excessive blood loss, was also withdrawn. The demographics and outcomes of the remaining 10 patients are detailed in Table 1.

Four patients developed clinical vasospasm and six did not. All patients with clinical vasospasm were female and this was significantly higher than in the nonvasospasm group $(\mathrm{P}<0.05)$. There was no statistically significant difference between patient age $(\mathrm{P}=0.18)$, Hunt and Hess grade at presentation $(\mathrm{P}=0.37)$ or Glasgow Outcome Score at discharge $(\mathrm{P}=0.15)$.

\section{Patients with Vasospasm (Figure 2)}

Four of 10 patients had clinical vasospasm with confirmed large vessel vasospasm angiographically (Figure 2: Patients 1-4). No patients had clinical vasospasm with negative angiography.

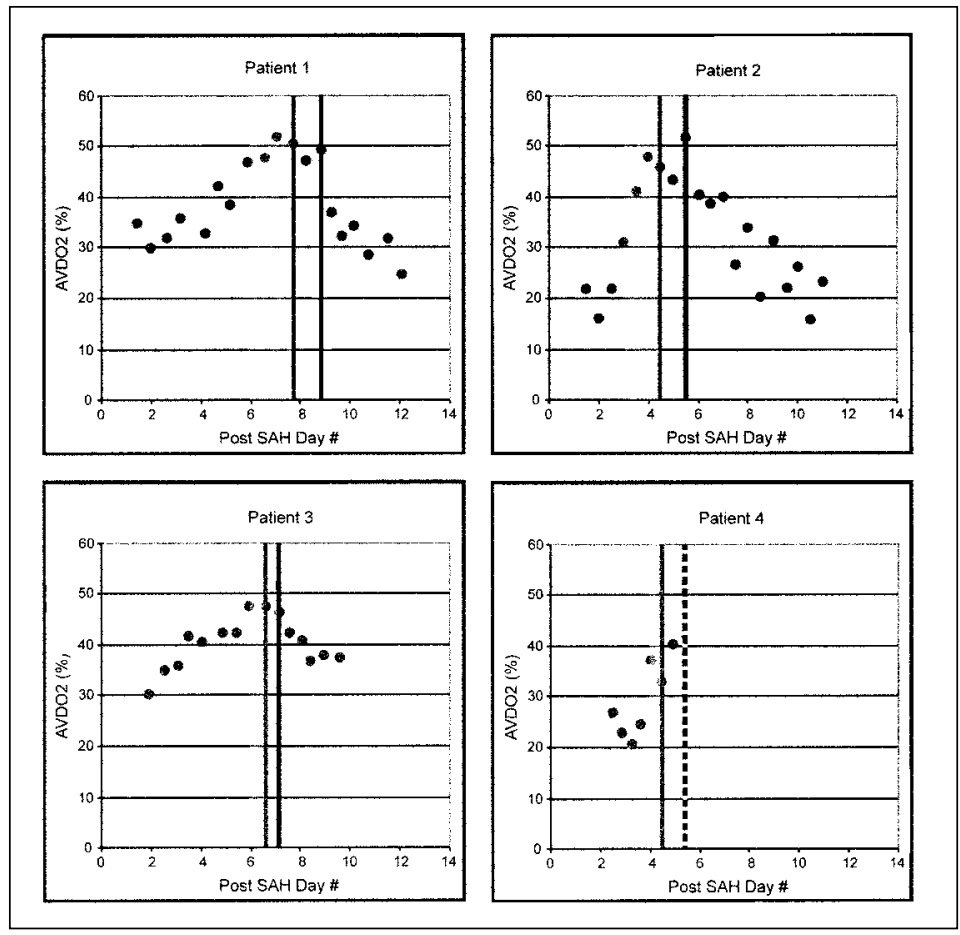

Figure 2: Patients with clinical vasospasm. A period of increasing AVDO (grey shading) is seen prior to clinical vasospasm (grey line). Note the improvement in $A V D O_{2}$ after the institution of HHH therapy (black line). In Patient 3, the black line refers to the addition of hypertension to previously initiated hypervolemic therapy. This paralleled clinical improvement. The 4th patient died (hatched line) after multiple infarcts related to vasospasm. 


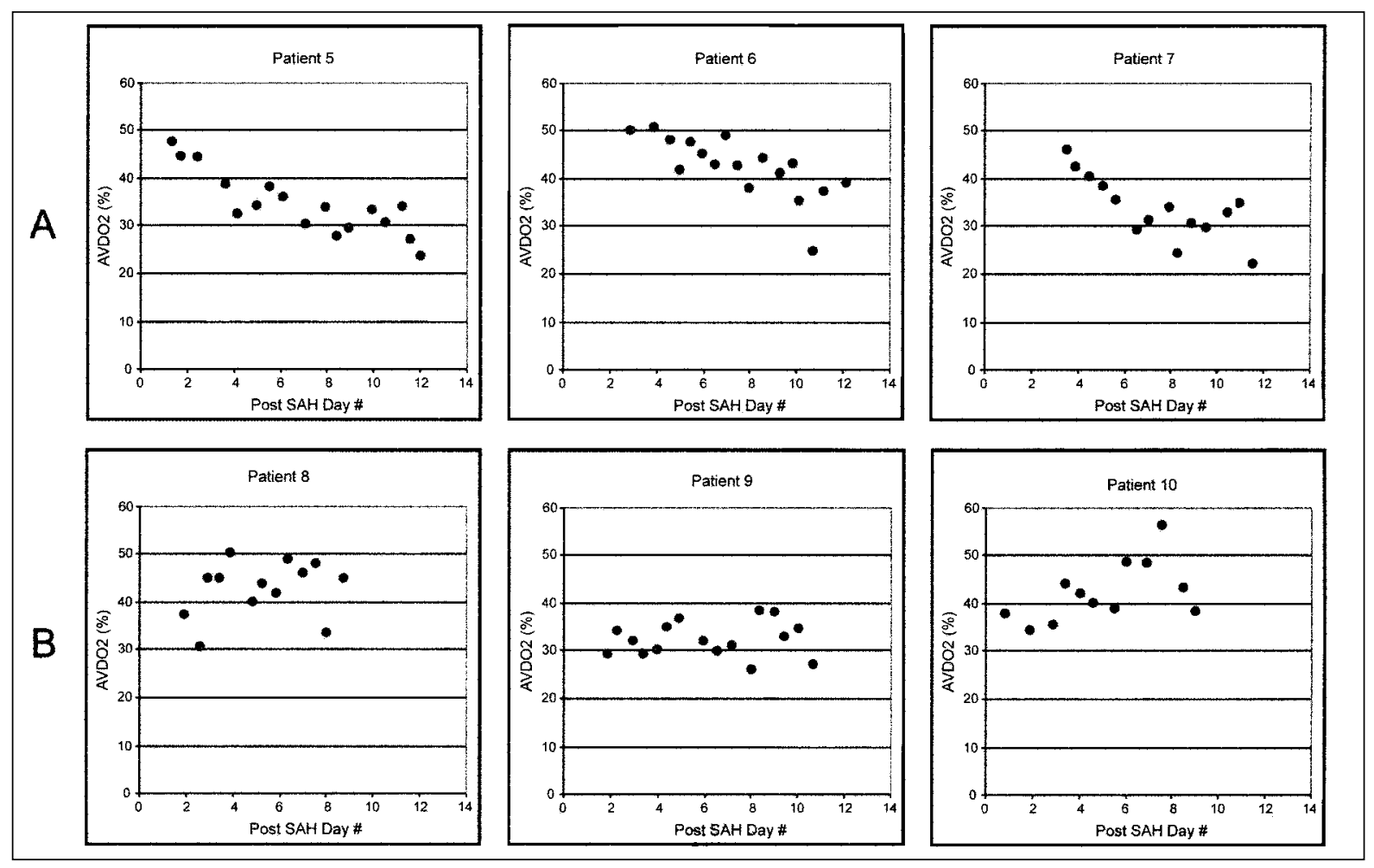

Figure 3: Patients without vasospasm. A) Patients without vasospasm demonstrating a gradual decline in AVDO are demonstrated. $B)$ Patients without clinical vasospasm demonstrating no specific trend in $\mathrm{AVDO} \mathrm{O}_{2}$ are demonstrated.

The four patients demonstrated a significant rise in oxygen extractions compared to baseline prior to onset of neurologic deficit $(\mathrm{P}<0.001)$ (Table 2). This change in metabolism predated the onset of clinical vasospasm by a mean of 26 hours (S.D. $=16$ hours, Range 12-47 hours). Patients 1 and 2 had treatment with $\mathrm{HHH}$ therapy after the confirmation of vasospasm with angiography. The clinical symptoms fully resolved along with an abrupt improvement in the oxygen extraction profile on instituting $\mathrm{HHH}$ therapy. Patient 3 had a planned angiogram performed and this demonstrated asymptomatic vasospasm without associated ischemic neurologic deficits. Because of the angiographic vasospasm, this patient was treated prophylactically for vasospasm with hypervolemic therapy. Despite this course of action, clinical symptoms of ischemia developed as $\mathrm{AVDO}_{2}$ continued to rise. However, more aggressive $\mathrm{HHH}$ therapy led to resolution of the deficits. Patients 1 through 3 all demonstrated a significant rapid improvement in oxygen extractions upon instituting $\mathrm{HHH}$ therapy $(\mathrm{P}=0.04)$ (Table 2). This improvement was sustained throughout the course of the study. Patient 4 had been clinically stable for four days, however early on the fifth day post-hemorrhage she became less responsive with increased focal neurologic deficits. Intracranial pressure as demonstrated by an external ventricular drainage device was less than $20 \mathrm{mmHg}$. A CT scan demonstrated multiple new low densities felt to be infarction secondary to vasospasm. Her status rapidly deteriorated and she died the following morning. Hypertensive, hemo-dilutional, and hypervolemic therapy was not instituted. Her oxygen extraction curve demonstrated a rise in extractions approximately 12 hours before clinical change.

\section{Patients without Vasospasm (Figure 3)}

Six of the 10 patients did not develop clinical vasospasm. Of these six patients, three demonstrated a significant gradual decline in $\mathrm{AVDO}_{2}$ with time towards normal values $(\mathrm{P}=0.007)$ (Figure 3A: Patients 5-7 and Table 2). The remaining three patients demonstrated no significant trend in $\mathrm{AVDO}_{2}(\mathrm{P}=0.16)$ (Figure 3B: Patients 8-10 and Table 2). An increase in $\mathrm{AVDO}_{2}$ was noted in Patient 10 at approximately eight days following hemorrhage with improvement thereafter. Four of these six patients had postoperative angiography to assess clip placement and none of these studies demonstrated angiographic vasospasm. Patient 10 did not have a postoperative angiography.

\section{Overview of $\mathrm{AVDO}_{2}$ with time}

Patients who suffered vasospasm had significantly lower $\mathrm{AVDO}_{2}$ at baseline than those who did not $(\mathrm{P}=0.029)$. However, at the time of exiting the vasospasm window, extractions were similar $(\mathrm{P}=0.32)$. Table 2 summarizes the mean $\mathrm{AVDO}_{2}$ seen amongst all patients relative to time.

\section{Complications}

There were no catheter related complications during the study. Furthermore, no complications attributable to therapy arose during the management of any patients during the duration of their hospital stay. 
Table 2: Change in mean oxygen extractions in patients with and without vasospasm over time.

\begin{tabular}{|c|c|c|c|c|c|}
\hline \multirow[t]{2}{*}{ Patients } & \multirow[t]{2}{*}{$\mathrm{N}$} & \multicolumn{4}{|c|}{ Mean \% Oxygen Extractions $\left(\mathrm{AVDO}_{2}\right)$} \\
\hline & & Baseline & $\begin{array}{l}\text { Symptomatic } \\
\text { Vasospasm }\end{array}$ & $\begin{array}{l}\text { Post-HHH } \\
\text { Therapy }\end{array}$ & $\begin{array}{l}\text { Resolution of } \\
\text { Vasospasm Window }\end{array}$ \\
\hline Group A & 3 & 46.3 & NA & NA & 30.7 \\
\hline Group B & 3 & 33.7 & NA & NA & 37.1 \\
\hline \multicolumn{6}{|c|}{$\begin{array}{l}\text { Patients with Vasospasm } \\
\text { versus Patients without }\end{array}$} \\
\hline Vasospasm - Total & & $\mathrm{P}=0.029$ & & & $\mathrm{P}=0.32$ \\
\hline
\end{tabular}

$\mathrm{HHH}=$ Hypertensive, hemo-dilutional, hypervolemic

NA $=$ Not applicable

*Analysis with Patient 4 excluded as Post Vasospasm data not available secondary to death.

\section{DISCUSSION}

\section{Jugular venous oximetry for predicting vasospasm in SAH}

In aneurysmal $\mathrm{SAH}$, the inability to consistently, safely, and economically predict the onset of clinical vasospasm has challenged neurosurgeons and critical care specialists alike. The reliable early prediction of vasospasm could allow the use of therapeutic measures, such as HHH therapy, angioplasty, and/or papaverine therapy, before cerebral ischemia ensues. This could potentially reduce morbidity related to DINDs by up to $80 \%^{13-15}$ and preclude the implementation of prophylactic therapies, ${ }^{11}$ that may carry their own associated morbidities. ${ }^{16}$

The most common theory that attempts to explain why vasospasm occurs in SAH patients is that increased cerebrovascular resistance from vascular changes, which may or may not be demonstrated on angiography or TCD, causes a distal reduction in cerebral blood flow (CBF). ${ }^{17-20}$ If a gradual reduction in $\mathrm{CBF}$ could be detected prior to potentially damaging ischemic changes by assessing the oxygen metabolism of the brain, then steps could be taken to act upon these changes and reduce the risk of DINDs. Progressive changes in oxygen metabolism occur before clinical symptoms and, hence, may have a high predictive value. Jugular venous sampling is safe, simple to perform, inexpensive to implement, and available in any hospital caring for patients with SAH. It is currently being used in many centers for the management of head injury in order to assess cerebral perfusion and the protocols used for placement and care is well-documented in the head injury literature, ${ }^{21}$ along with its safety, ${ }^{22}$ and will not be further discussed. A brief discussion of the rationale behind jugular venous oximetry is given below.

\section{Rationale}

The cerebral metabolic rate of oxygen $\left(\mathrm{CMRO}_{2}\right)$ is balanced with the $\mathrm{CBF}$ as demonstrated by changes in oxygen saturations of blood from the jugular bulb $\left(\mathrm{SjvO}_{2}\right){ }^{23}$ Changes of the $\mathrm{SjvO}_{2}$ reflect the balance between $\mathrm{CBF}$ and the $\mathrm{CMRO}_{2}$. As the $\mathrm{CBF}$ decreases, there is a reduction in the $\mathrm{SjvO}_{2}$ and vice versa. The $\mathrm{CEO}_{2}$ is given by the subtraction of $\mathrm{SjvO}_{2}$ from the arterial oxygen saturation $\left(\mathrm{SaO}_{2}\right)$ and is equivalent to the $\mathrm{AVDO}_{2}($ Figure 1). Therefore, $\mathrm{AVDO}_{2}$ is closely related to $\mathrm{CBF}$, increasing with reductions in $\mathrm{CBF}$ and decreasing with increases in $\mathrm{CBF}^{24}$

The normal CBF of $50 \mathrm{ml} / 100 \mathrm{~g} / \mathrm{min}$ of tissue must drop to less than $20 \mathrm{ml} / 100 \mathrm{gm} / \mathrm{min}$ to get neuronal activity reduction and reversible neuronal changes and to less than $10 \mathrm{ml} / 100 \mathrm{gm} / \mathrm{min}$ to get irreversible neuronal damage. ${ }^{25,26}$ A decline in $\mathrm{SjvO}_{2}$ to below $50 \%$ is considered indicative of cerebral ischemia in comatose patients (also shown to correlate with vasospasm and reduced cerebral perfusion pressure in SAH). ${ }^{27}$ With reduction in $\mathrm{CBF}$, there is proportionately increasing oxygen extraction from delivered blood. Furthermore, in brain starving for oxygen, at a threshold of greater than $50 \%$ reduction in $\mathrm{CBF}$, or close to the level of $\mathrm{CBF}$ reduction associated with clinical changes, there is an increase in lactate production from anaerobic metabolism. ${ }^{24,28}$

\section{Previous use in SAH}

Jugular venous oximetry has been used occasionally in aneurysmal SAH as a tool to identify changes in cerebral oxygen metabolism with treatment but it has not specifically been used to help predict ischemic deficits before they occur. Von Helden et $\mathrm{al}^{29}$ have demonstrated that the $\mathrm{SjvO}_{2}$ could be valuable for monitoring cerebral ischemia in SAH. They described a patient that had an $\mathrm{SjvO}_{2}$ of $60 \%$ initially with a drop to $55 \%$ when TCD demonstrated an increase in flow velocity consistent with vasospasm. Later, the flow velocity increased further, the AVDL was noted to increase, and $\mathrm{SjvO}_{2}$ fell below $50 \%$. The patient suffered from infarction and finally died. Fandino et $\mathrm{al}^{13}$ have further confirmed the ability of jugular bulb oximetry to detect the cerebral oxygenation patterns in vasospasm and to differentiate these patterns from nonvasospastic conditions that may also occur in $\mathrm{SAH}$. They assessed $\mathrm{SjvO}_{2}$ before, during, and after intra-arterial infusion of papaverine, with or without balloon angioplasty, in patients with symptomatic vasospasm. 
Twenty-three vascular territories in 10 patients were treated. A significant improvement in $\mathrm{SjvO}_{2}$ was observed in all cases, with an improvement in cerebral oxygenation after endovascular treatment of vasospasm $(\mathrm{p}=0.005)$. In his study, there was no attempt to use jugular venous oximetry as an aid to detect or predict vasospasm.

Few studies have been performed demonstrating the baseline $\mathrm{AVDO}_{2}$ seen specifically in SAH prior to vasospasm and the results have neither been consistent nor clear. Gibbs ${ }^{30}$ studied 50 normal young males and found an $\mathrm{SvjO}_{2}$ mean of $61.8 \%$ with a range of $55-71 \%$. Kawamura et al $^{31}$ studied nine patients with $\mathrm{SAH}$ and demonstrated that in the prespasm stage the brain was relatively hyperemic with close to normal $\mathrm{CBF}$ and lower than normal $\mathrm{CMRO}_{2}$ compared with the vasospasm stage when $\mathrm{CMRO}_{2}$ became reduced in parallel with $\mathrm{CBF}$. Another small study looking at CBF described two SAH patients with elevated $\mathrm{SvjO}_{2}$, however the association with clinical status was not addressed. ${ }^{32}$

\section{Analysis of our results}

This study has confirmed the ability of jugular venous oximetry to predict the onset of clinical vasospasm in a small group of patients. In the four patients who developed clinical vasospasm, a significant increase $(\mathrm{P}<0.001)$ in cerebral $\mathrm{AVDO}_{2}$ was demonstrated at a mean of 26 hours before clinical changes were noted. This was not seen in those patients who did not develop clinical vasospasm. A statistically significant improvement in $\mathrm{AVDO}_{2}$ in patients with clinical vasospasm occurred rapidly in response to $\mathrm{HHH}$ therapy $(\mathrm{P}=0.04)$. The expected preclinical vasospasm rise in oxygen extractions was not as marked in Patient 3 as the patient was treated with prophylactic $\mathrm{HHH}$ therapy after a planned angiogram demonstrated angiographic spasm, hence possibly improving the extraction profile. Three of the six patients not affected by vasospasm actually had a significant decline $(\mathrm{P}=0.007)$ in $\mathrm{AVDO}_{2}$ over the course of monitoring, suggesting an improvement in cerebral oxygen metabolism or perfusion after the initial insult from SAH. Of the remaining three individuals, two demonstrated relatively stable $\mathrm{AVDO}_{2}$ over the course of monitoring. The third, Patient 10, may have been on the brink of clinical vasospasm as this patient demonstrated a rather subtle rise in extractions towards day seven and eight that subsequently improved over the next several days. This patient represented the only false positive for predicting clinical vasospasm in our study. If the results were acted upon, we would have treated the patient with potentially detrimental $\mathrm{HHH}$ therapy and performed an angiogram which has its own inherent risks. There were no false negatives for prediction of vasospasm in our study. Further study with a larger group of patients may better clarify the sensitivity and specificity of jugular venous oximetry for predicting vasospasm.

Baseline $\mathrm{AVDO}_{2}$ was $27.6 \%$ in the vasospasm group and $40.0 \%$ in the nonvasospasm group. This value was significantly different $(\mathrm{P}=0.029)$ but the reason for this is not clear. A speculation could be made that patients with higher initial extractions as seen in the nonvasospasm group may have had worse grade $\mathrm{SAH}$, raised ICP or ischemic insult at the time of hemorrhage. This did not appear to be the case as these patient characteristics and outcomes did not significantly differ (Table
1). Of note though is that there was no difference in extractions at the time of removing the jugular venous catheters; $29.2 \%$ and $33.9 \%$ for the vasospasm and nonvasospasm groups, respectively $(\mathrm{P}=0.32)$. This value is consistent with the literature for oxygen extractions seen in normal individuals, as are the initial extractions seen in the vasospasm group. ${ }^{30}$

This may suggest that there is no definitive predictive oxygen extraction profile occurring in the first few days after SAH. However, low initial $\mathrm{AVDO}_{2}$ may alert to impending vasospasm. In fact, there may be a period of hyperemia or depressed metabolism in patients succumbing to vasospasm clinically prior to the peak demonstrated in our study. Metabolic depression has been suggested and confirmed by positron emission tomography studies. ${ }^{17,33,34}$ Jakobsen and Carpenter have each disputed the role of this nonischemic depression in metabolism feeling the relative hyperemia is secondary to ischemic damage to the brain from the initial intracranial pressure increase from SAH. ${ }^{19,35}$ This has shown good correlation with the grade of initial hemorrhage. ${ }^{35}$ As discussed earlier, in our study, no correlation between initial clinical grades of hemorrhage, early ischemic lesions or raised ICP could be made with our small number of patients. Further study is necessary to address the relation between baseline extractions and vasospasm.

\section{Methods of improvement}

Continuous oximetry may allow better assessment of jugular venous oxygen levels than intermittent measures, as performed in this study, and could further negate our technical failures. ${ }^{36,37}$ These new regional oxygen saturation catheters, providing reliable measurement of $\mathrm{SjvO}_{2}$ for continuous monitoring of $\mathrm{SjvO}_{2}$, are being used extensively for the management of severe head injury. ${ }^{38}$ However, jugular bulb blood may not be globally representative of cerebral venous drainage as incomplete mixture of blood draining different regions of the brain as well as the entrance of extracranial venous blood into the cerebral drainage is acknowledged. ${ }^{39,40}$ Dependence of values on the side of catheter placement must also be considered. ${ }^{12}$ Since the assessment is from pooled blood, normal surrounding areas may mask a local change, thus reducing the sensitivity of jugular bulb venous oximetry. In the future, monitoring of CBF by near infrared spectroscopy ${ }^{41}$ parenchymal probes and microdialysis systems ${ }^{42}$ may allow regional hypoxia surveillance; however, they are invasive to the brain and expensive. The monitoring of acid base balance in the cerebrospinal fluid has shown some value. ${ }^{43}$

\section{Conclusions}

We have demonstrated, in a small group of patients, that jugular bulb oximetry is simple and effective in predicting the onset of clinical vasospasm. Cerebral oxygen extractions steadily declined (improved) in patients not developing clinical vasospasm. A rise in oxygen extraction (worsening) was seen approximately one day prior to and during clinical vasospasm with subsequent decline with $\mathrm{HHH}$ therapy; this provides a potential therapeutic window. A steady increase in cerebral oxygen extractions was predictive of clinical vasospasm in our small group. This investigation clearly makes a good model for a larger study to assess the utility of jugular bulb oximetry in predicting vasospasm in $\mathrm{SAH}$ and the resultant effect of treatment implementation on outcome. 


\section{REFERENCES}

1. Dietrich HH, Dacey RG Jr. Molecular keys to the problems of cerebral vasospasm. Neurosurgery 2000;46(3):517-530.

2. Schucknecht B, Fandino J, Yuksel C, Yonekawa Y, Valavanis A. Endovascular treatment of cerebral vasospasm: assessment of treatment effect by cerebral angiography and transcranial Doppler sonography. Neuroradiology 1999;41:453-462.

3. Charpentier C, Audibert G, Guillemin F, et al. Multivariate analysis of predictors of cerebral vasospasm occurrence after aneurysmal subarachnoid hemorrhage. Stroke 1999;30(7):1402-1408.

4. Papavasiliou AK, Harbaugh KS, Birkmeyer NJ, et al. Clinical outcomes of aneurysmal subarachnoid hemorrhage patients treated with oral diltiazem and limited intensive care management. Surg Neurol 2001;55(3):138-146; discussion 146147.

5. Turjman F, Mimon S, Yilmaz H. [Epidemiology, clinical study and pathology of vasospasm]. J Neuroradiol 1999;26(1 Suppl):S10S16.

6. Fisher CM, Kistler JP, Davis JM. Relation of cerebral vasospasm to subarachnoid hemorrhage visualized by computerized tomographic scanning. Neurosurgery 1980;6(1):1-9.

7. Rordorf G, Koroshetz WJ, Copen WA, et al. Diffusion- and perfusion-weighted imaging in vasospasm after subarachnoid hemorrhage. Stroke 1999;30(3):599-605.

8. Busch E, Beaulieu C, de Crespigny A, Moseley ME. Diffusion MR imaging during acute subarachnoid hemorrhage in rats. Stroke 1998;29(10):2155-2161.

9. Rowe J, Blamire AM, Domingo Z, et al. Discrepancies between cerebral perfusion and metabolism after subarachnoid haemorrhage: a magnetic resonance approach. J Neurol Neurosurg Psychiatry 1998;64(1):98-103.

10. Powsner RA, O'Tuama LA, Jabre A, Melhem ER. SPECT imaging in cerebral vasospasm following subarachnoid hemorrhage. J Nucl Med 1998;39(5):765-769.

11. Egge A, Waterloo K, Sjoholm H, et al. Prophylactic hyperdynamic postoperative fluid therapy after aneurysmal subarachnoid hemorrhage: a clinical, prospective, randomized, controlled study. Neurosurgery 2001;49(3):593-605; discussion 605-606.

12. Gibbs EL, Gibbs FA. The cross section areas of the vessels that form the torcular and the manner in which blood is distributed to the right and to the left lateral sinus. Anat Rec 1934;54:419.

13. Fandino J, Kaku Y, Schuknecht B, Valavanis A, Yonekawa Y. Improvement of cerebral oxygenation patterns and metabolic validation of superselective intraarterial infusion of papaverine for the treatment of cerebral vasospasm. J Neurosurg 1998;89(1):93-100.

14. Kassell NF, Helm G, Simmons N, Phillips CD, Cail WS. Treatment of cerebral vasospasm with intra-arterial papaverine. J Neurosurg 1992;77(6):848-852.

15. Firlik AD, Kaufmann AM, Jungreis CA, Yonas H. Effect of transluminal angioplasty on cerebral blood flow in the management of symptomatic vasospasm following aneurysmal subarachnoid hemorrhage. J Neurosurg 1997;86(5):830-839.

16. Levy ML, Giannotta SL. Cardiac performance indices during hypervolemic therapy for cerebral vasospasm. J Neurosurg 1991;75(1):27-31.

17. Voldby B, Enevoldsen EM, Jensen FT. Regional CBF, intraventricular pressure, and cerebral metabolism in patients with ruptured intracranial aneurysms. J Neurosurg 1985;62(1):48-58.

18. Jakobsen M, Overgaard J, Marcussen E, Enevoldsen EM. Relation between angiographic cerebral vasospasm and regional CBF in patients with SAH. Acta Neurol Scand 1990;82(2):109-115.

19. Carpenter DA, Grubb RL Jr, Tempel LW, Powers WJ. Cerebral oxygen metabolism after aneurysmal subarachnoid hemorrhage. J Cereb Blood Flow Metab 1991;11(5):837-844.

20. Grubb RL Jr, Raichle ME, Eichling JO, Gado MH. Effects of subarachnoid hemorrhage on cerebral blood volume, blood flow, and oxygen utilization in humans. J Neurosurg 1977;46(4):446-453.

21. Cruz J. The first decade of continuous monitoring of jugular bulb oxyhemoglobin saturation: management strategies and clinical outcome. Crit Care Med 1998;26:344-351.
22. Coplin WM, O'Keefe GE, Grady MS, et al. Thrombotic, infectious, and procedural complications of the jugular bulb catheter in the intensive care unit. Neurosurgery 1997;41(1):101-107; discussion 107-109.

23. Kety SS, Schmidt CF. The nitrous oxide method for the quantitative determination of cerebral blood flow in man: theory, procedure and normal values. J Clin Invest 1948;27:476-483.

24. Robertson CS, Narayan RK, Gokaslan ZL, et al. Cerebral arteriovenous oxygen difference as an estimate of cerbral blood flow in comatose patients. J Neurosurg 1989;70:222-230.

25. Jones TH, Morawetz RB, Crowell RM. Thresholds of focal cerebral ischemia in awake monkeys. J Neurosurg 1981;54:773-782.

26. Hossman KA, Schuier FJ. Experimental braininfarcts in cats. 1. Pathophysiolgoical observations. Stroke 1980;11:583-592.

27. Schneider GH, von Helden A, Lanksch WR, Unterberg A. Continuous monitoring of jugular bulb oxygen saturation in comatose patients - therapeutic implications. Acta Neurochir 1995;134(1-2):71-75.

28. Lassen NA. The luxury-perfusion syndrome and its possible relation to acute metabolic acidosis localized within the brain. Lancet 1996;2:1113-1115.

29. von Helden A, Schneider GH, Unterberg A, Lanksch WR. Monitoring of jugular venous oxygen saturation in comatose patients with subarachnoid hemorrhage and intracerebral hematomas. Acta Neurochir Suppl (Wien) 1993;59:102-106.

30. Gibbs EL, Lennox WG, Nims LF, Gibbs FA. Arterial and cerebral venous blood. Arterial-venous difference in man. J Biol Chem 1942;144:325-332.

31. Kawamura S, Sayama I, Yasui N, Uemura K. Sequential changes in cerebral blood flow and metabolism in patients with subarachnoid haemorrhage. Acta Neurochir 1992;114(1-2):1215.

32. Miller JI, Chou MW, Capocelli A, et al. Continuous intracranial multimodality monitoring comparing local cerebral blood flow, cerebral perfusion pressure, and microvascular resistance. Acta Neurochir Suppl (Wien) 1998;71:82-84.

33. Hino A, Mizukawa N, Tenjin H, et al. Postoperative hemodynamic and metabolic changes in patients with subarachnoid hemorrhage. Stroke 1989;20(11):1504-1510.

34. Powers WJ, Grubb RL Jr, Baker RP, Mintun MA, Raichle ME. Regional cerebral blood flow and metabolism in reversible ischemia due to vasospasm. Determination by positron emission tomography. J Neurosurg 1985;62(4):539-546.

35. Jakobsen M, Enevoldsen E, Bjerre P. Cerebral blood flow and metabolism following subarachnoid haemorrhage: cerebral oxygen uptake and global blood flow during the acute period in patients with SAH. Acta Neurol Scand 1990;82(3):174-182.

36. Sheinberg M, Kanter MJ, Robertson CS, et al. Continuous monitoring of jugular venous oxygen saturation in head- injured patients. J Neurosurg 1992;76(2):212-217.

37. Coplin WM, O'Keefe GE, Grady MS, et al. Accuracy of continuous jugular bulb oximetry in the intensive care unit. Neurosurgery 1998;42(3):533-9; discussion 539-540.

38. Ritter AM, Gopinath SP, Contant C, Narayan RK, Robertson CS. Evaluation of a regional oxygen saturation catheter for monitoring $\mathrm{SjvO}_{2}$ in head injured patients. J Clin Monit 1996;12(4):285-291.

39. Shenkin GA, Harmel MH, Kety SS. Dynamic anatomy of the cerebral circulation. Arch Neurol Psych 1948;60:240-252.

40. Matta BF, Lam AM. The rate of blood withdrawal affects the accuracy of jugular venous bulb oxygen saturation measurements. Anesthesiology 1997;86(4):806-808.

41. Ogata N, Mijake H, Ogata K, et al. Intraoperative monitoring during carotid cross-clamping with near infrared spectroscopy: a preliminary study. J Biomed Optics 1996;1(4):405-413.

42. Persson L, Hillered L. Chemical monitoring of neurosurgical intensive care patients using intracerebral microdialysis. J Neurosurg 1992;76(1):72-80.

43. Meixensberger J, Jager A, Dings J, Baunach S, Roosen K. Multimodal hemodynamic neuromonitoring - quality and consequences for therapy of severely head injured patients. Acta Neurochir Suppl 1998;71:260-262. 